\title{
EDUCAÇÃO MATEMÁTICA E EDUCAÇÃO INFANTIL: UMA PROPOSTA DE FORMAÇÃO CONTINUADA NA ABORDAGEM HISTÓRICO-CULTURAL
}

\author{
MATHEMATICS EDUCATION AND CHILDHOOD EDUCATION: A PROPOSAL FOR \\ CONTINUING EDUCATION IN THE HISTORICAL-CULTURAL APPROACH
}

\author{
EDUCACIÓN MATEMÁTICA Y EDUCACIÓN INFANTIL: UNA PROPUESTA DE \\ FORMACIÓN CONTINUA EM EL ENFOQUE HISTÓRICO-CULTURAL
}

\author{
FABIANY CEZÁRIO DIAS TOREZANI ${ }^{1}$ \\ DAYANE DE SOUZA GOMES ${ }^{2}$ \\ DILZA CÔCO ${ }^{3}$
}

\section{RESUMO}

0 artigo apresenta resultados de pesquisa sobre a formação continuada com professores que ensinam matemática na Educação Infantil, cujo campo empírico se refere a um curso de extensão, ofertado em 2018, pelo Instituto Federal do Espírito Santo -Vitória. Participaram do curso 26 docentes interessados em aprofundar conhecimentos sobre grandezas e medidas e número natural. Neste artigo, buscamos evidenciar relações entre ações de estudos coletivos propostos na formação e o processo de mudança de qualidade na organização do trabalho pedagógico dos participantes. Para isso, toma-se como fundamento teórico metodológico os pressupostos da abordagem Histórico-Cultural, especialmente contribuições da Teoria da Atividade e da Atividade Orientadora de Ensino. 0 conjunto dos dados, registrados por meio de videogravação, fotografias, textos escritos e outros recursos, e estruturados na forma de episódios e cenas. As análises indicam que os estudos coletivos influenciaram a reorientação dos planejamentos pedagógicos, revelando outra qualidade para as ações didáticas.

Palavras-chave: Formação continuada de professores. Educação infantil. Teoria Histórico-Cultural. Grandezas e medidas. Número natural.

\section{ABSTRACT}

The article presents results of the research regarding the continuing formation with who teach mathematics in childhood education, whose empirical field refers itself to an extension course offered in 2018, by the Federal Institute of Espirito Santo-Vitória. Took part in the course 26 teachers interested in deepening knowledge about measures of quantities and natural numbers. In this article, we seek to highlight connections between the collective studies proposed in the formation, and the process of changing quality in the organization of the pedagogical work presented by the participants. For this, it is taken as theoretical methodological foundation the assumptions of the historical-cultural approach, especially collaborations of the activity theory and the oriented teaching activity. The set of dada registered on video, photos, written texts and other resources, and structured as episodes and scenes. The analysis indicate that the collective studies influenced the reorientation of the pedagogical planning, revealing another quality to the didactic actions.

Keywords: Teachers' continuing formation. Childhood education. Historical-cultural theory. Quantities and measures. Natural numbers.

1 Mestre em Educação. Prefeitura Municipal de Vila Velha-ES. E-mail: fcdtorezani@edu.vilavelha.es.gov.br. Orcid: https://orcid.org/ 0000-0001-8059-8046

2 Mestre em Educação. Prefeitura Municipal de Serra-ES. E-mail: dayane.desouza@yahoo.com.br. Orcid: https://orcid.org/0000-0002-2744-4221 3 Doutora em Educação. Instituto Federal do Espírito Santo. E-mail: dilzacoco@gmail.com. Orcid: https://orcid.org/0000-0001-8371-8517 


\section{RESUMEN}

El artículo presenta los resultados de la investigación sobre formación continua con profesores que enseñan matemáticas en la educación infantil , cuyo campo empírico se refiere a un curso de extensión, ofrecido en 2018, por el Instituto Federal do Espírito Santo - Vitória. 26 profesores participarón en el curso, interesados en profundizar el conocimiento sobre magnitudes y medidas y número natural. En este artículo buscamos mostrar la relación entre las acciones de los estudios colectivos propuestos en la capacitación y el proceso de cambio de calidad en la organización del trabajo pedagógico de los participantes. Para este fin, los supuestos del enfoque Histórico-Cultural se toman como una base teórica y metodológica, especialmente las contribuciones de la Teoría de la Actividad y la Actividad Orientadora de la Enseñanza. El conjunto de datos, grabados por video, fotografías, textos escritos y otros recursos, están estructurados en forma de episodios y escenas. Los análisis indican que los estudios colectivos influyeron en la reorientación de la planificación pedagógica, revelando otra cualidad para las acciones didáticas.

Palabras-clave: Formación continua de profesores. Educación infantil. Teoria Histórico-Cultural. Magnitudes y medidas. Numero Natural.

\section{INTRODUÇÃO}

A formação docente no Brasil constitui campo amplo de discussões que revelam disputas, tensões, conflitos, bem como possibilidades para estudos e pesquisas variadas. Além disso, guarda potencial para atualizações constantes à medida que novos problemas e necessidades surgem no campo educacional. Conforme Saviani (2009) evidencia, desde a criação das escolas de primeiras letras em 1827, a questão da formação qualificada para o trabalho educativo tem fomentado preocupações governamentais em razão de uma complexa realidade social. Outras formulações legais foram sendo processadas, alcançando um grau importante de discussões com a promulgação da Lei de Diretrizes e Bases da Educação Nacional no 9394/1996, que definiu a universidade como o lócus da formação de professores para a educação básica. Cabe destacar que, em termos de políticas públicas, outra iniciativa importante para ampliar as oportunidades de oferta de cursos em nível superior para a formação de professores se concretizou com a promulgação da Lei $n^{0} 11.892 / 2008$. Essa lei reconfigurou os objetivos e as finalidades da rede federal, composta pelos Institutos Federais (IFs), definindo como um dos eixos de ação a formação de professores. Com base nessa nova regulamentação, os IFs passaram a oferecer cursos de licenciatura, em especial com ênfase nas áreas de ciências e matemática.

É nesse contexto que o Instituto Federal do Espírito Santo passa a atuar nessa área, tanto na dimensão da formação inicial como em ações de formação continuada. Em relação à formação inicial, a oferta do curso de licenciatura em Matemática, a partir de 2008, constituiu um marco inaugural, tendo em vista a longa e reconhecida trajetória centenária da instituição dedicada, até então, exclusivamente a formação profissional e tecnológica. Em 2011, avançou para ações na pós-graduação com a oferta do curso de mestrado profissional em Educação em Ciências e Matemática e, recentemente, a aprovação do doutorado profissional pela Coordenação de Aperfeiçoamento de Pessoal de nível superior (Capes) para iniciar a primeira turma em 2021. Articulados a esses cursos, vários grupos de pesquisas foram criados, entre os quais o Grupo de Pesquisa em Práticas Pedagógicas de Matemática (Grupem). Esse grupo envolve licenciandos, mestrandos, professores da educação básica e professores pesquisadores em projetos científicos, que articulam ensino, pesquisa e extensão. Esses projetos tematizam práticas pedagógicas e ações de formação de 
professores baseados em pressupostos da Teoria Histórico-Cultural, com especial destaque para discussões sobre a Educação Matemática.

Com esse propósito, 0 grupo efetiva 0 estreitamento das duas dimensões da formação docente, a formação inicial e a continuada, e estabelece vínculos entre a instituição formadora e escolas de educação básica. Nesse sentido, vem desenvolvendo diferentes ações na forma de oficinas pedagógicas para estudantes da rede pública ou cursos de extensão direcionados a professores da educação básica. 0 primeiro curso ofertado discutiu conceitos de geometria (2015, 110 inscritos), o segundo explorou conhecimentos de grandezas e medidas em articulação com a literatura infantil (2015, 160 inscritos), o terceiro abordou 0 conceito de frações (2016, 154 inscritos) e 0 quarto trabalhou conhecimentos envolvidos nos conceitos de multiplicação e divisão (2017, 542 inscritos). Todos esses cursos tiveram como público-alvo professores dos anos iniciais do ensino fundamental. Nessas várias experiências, foram apreendidos também 0 interesse e demandas formativas dos professores da Educação Infantil em relação ao ensino de matemática. Assim, em 2018, foi ofertado um curso de extensão para esse grupo de profissionais, com o objetivo de discutir e aprofundar conhecimentos sobre a matemática na Educação Infantil, em especial conceitos de números naturais e de grandezas e medidas. Tais estudos foram desenvolvidos com 26 professoras por meio de encontros coletivos e presenciais, realizados no Laboratório de Ensino de Matemática (LEM) do instituto, tarefas a distância, no intuito de subsidiar novos conhecimentos teóricos e metodológicos sobre tais conhecimentos, desenvolvimento de tarefas em salas de aulas das professoras participantes e encontros reflexivos sobre as ações desenvolvidas. Em dois dias destinados às inscrições, foram registrados 179 interessados, o que indica uma grande demanda. Os 11 encontros presenciais ocorreram entre setembro e dezembro de 2018, com quatro horas de duração cada um. A carga horária total da formação foi constituída de 80 horas.

Situadas essas várias experiências de formação continuada com professores que ensinam matemática, neste artigo privilegiamos discussões específicas sobre os dados produzidos na última ação descrita, ou seja, com os professores da educação infantil. Assim, para este texto, delimitamos como objetivo evidenciar relações entre ações de estudos coletivos propostos na formação e o processo de mudança de qualidade na organização do trabalho pedagógico dos participantes. Para isso, estruturamos 0 artigo em quatro partes, incluindo esta introdução e as considerações finais. Na segunda seção, explicitamos os fundamentos teóricos metodológicos da abordagem Histórico-Cultural que orientaram a organização e o desenvolvimento da referida formação docente. Na sequência, na terceira seção, apresentamos dois episódios, um sobre grandezas e medidas e outro sobre o número natural, para evidenciar o movimento de aprendizagem das participantes, estimuladas pelos estudos coletivos e influências no processo de organização do ensino.

Esperamos que essas discussões contribuam para apontar potencialidades de parcerias e de diálogos entre a instituição formadora e profissionais da educação básica na produção de conhecimentos no campo da formação docente. Além disso, buscam indicar a importância de ações que integram ensino, pesquisa e extensão, como uma das possibilidades de realizar ações formativas que apostam na indissociabilidade entre teoria e prática. Cabe realçar que tais aspectos foram valorados como princípios orientadores para a formação docente na resolução do Conselho Nacional de Educação (CNE) 02/2015, a qual, no período da pesquisa, estava vigente. Assim, esperamos que as análises tecidas neste artigo reafirmem proposições dessa resolução e ainda sirvam para contrapor regulamentações que minimizem a atuação das instituições de nível superior, em especial as públicas, no contexto da formação docente. 


\section{DIÁLOGOS COM A ABORDAGEM HISTÓRICO-CULTURAL NO CAMPO DE ESTUDOS DA FORMAÇÃO DE PROFESSORES}

Os pressupostos teórico-metodológicos oriundos da abordagem Histórico-Cultural têm fundamentado diferentes estudos e pesquisas sobre a formação docente no cenário acadêmico nacional com alguns autores, como Saviani (2019), Martins (2015), Moura (2000; 2001; 2010), Moretti e Moura (2010; 2011), Araújo (2014), Lopes (2009), Cedro (2008), Gladcheff (2015), entre muitos outros. No âmbito internacional, também temos uma expressão considerável de pesquisas subsidiadas por essa teoria, haja vista as publicações apresentadas no evento internacional Society for Cultural-Historical Activity Research (ISCAR), em suas cinco edições realizadas em várias cidades, como em Sevilha (2005), San Diego (2008), Roma (2011), Sidney (2014) e Quebec (2017). De modo mais próximo com as produções internacionais, temos dialogado com proposições de Radford (2017) e Beatón (2017). Esses estudos indicam a atualidade desse aporte teórico para pensarmos as demandas educacionais de nosso tempo. Assim, em nossas ações de estudos, pesquisas e extensão, também nos alinhamos com as contribuições de Vigotski (2010), de Leontiev (1984) e com o conceito de Atividade Orientadora de Ensino desenvolvido por Moura (1996; 2010) e Moura et al. (2010). Por intermédio desses autores, entendemos que o processo de aprendizagem deve ser concebido como processo de humanização, em que o sujeito se desenvolve, ao participar de situações que estimulem a apropriação de conhecimentos em uma abordagem lógico-histórica.

Assumimos a compreensão de que esse desenvolvimento ocorre por meio de relações sociais, coletivas e organizadas intencionalmente, nas quais a linguagem constitui um componente fundamental para a mediação dos conhecimentos e da cultura. Em nossa sociedade moderna, esse processo de desenvolvimento acontece de modo especial no espaço-tempo das instituições educativas (escolas, universidades, bibliotecas, entre outras), as quais sintetizam as formas mais elaboradas e criativas que a humanidade inventou para guardar e/ou preservar o acervo de conhecimentos. A escola, em especial, constitui um espaço-tempo privilegiado para imprimir marcas do humano no humano e, assim, promover relações e apropriações de conhecimentos. Desse modo, a escola assume a função de compartilhar 0 acervo cultural com as novas gerações. É oportuno destacar também que concebemos a escola como lugar onde pessoas atuam, convivem, vivem, se organizam, trabalham e se relacionam com as mais variadas formas de conhecimentos da arte, da ciência e da filosofia. Assumimos que esses conhecimentos variados apresentam uma história e iniciam com necessidades humanas. As soluções encontradas pelos homens para os desafios da produção da vida e da cultura acumulam um conjunto de conhecimentos que alimentam novas produções cada vez mais específicas.

No cenário dessas discussões e do processo de especialização das atividades humanas, encontra-se 0 trabalho do professor, que assume uma função estratégica e de caráter eminentemente social, pois prepara todos os demais profissionais, inclusive os de sua classe. De modo direto, trabaIha para 0 desenvolvimento de pessoas singulares, mas indiretamente seu trabalho atende a necessidades coletivas que podem ser atualizadas a cada geração ou conforme as demandas que surgem na sociedade. Assim, o trabalho do professor apresenta caráter dinâmico e passível de constante modificação, o que requer uma formação ampla e contínua. Contudo, é importante considerar que a formação contínua de professores, conforme advertem Franco e Longarezi (2011), deve ser assumida pelo docente como uma atividade que promove desenvolvimento pessoal e, consequentemente, altera suas condições de organização do seu trabalho. Não deve ser entendida como apenas uma necessidade emergente do mercado, fora de sua atividade docente. Nesse sentido, 
Formação continuada em programas e/ou projetos a partir dos quais o professor não 0 assume, por condições inerentes à sua natureza de ser social, como desejo de autorealização, de necessidade formativa, com significação social e sentido pessoal, mas tão somente por exigência do mercado competitivo, por demanda legal ou governamental, passa a ser alienado e alienante, o que é ainda pior (FRANCO; LONGAREZI, 2011, p. 564).

Ao contrário de ser alienante, a formação do docente deve ser constituída levando em conta necessidades do professor, motivadas tanto pelo interesse pessoal ou coletivo quanto pela busca de promoção de um nível mais elevado de conhecimento para melhorar seu trabalho. Desse modo, é possível que o processo formativo seja significante para o docente, possibilitando uma aprendizagem efetiva. Tomar as necessidades do docente, bem como as de quem promove o processo formativo, contribui para a caracterização da formação como fenômeno, pois implica "compreender algo (a formação contínua) que não está dado, não está posto" (MOURA, 2000, p. 45 - grifo nosso). Porém, vai ser constituído mediante necessidades que motivaram os sujeitos a participar ativamente no processo de mediação de conhecimento teórico e prático, por meio das relações estabelecidas no coletivo, formado por sujeitos dotados com a mesma motivação.

De acordo com Moura (2000), a pesquisa que toma como objeto a formação de professores deve buscar apreender "o modo como o fenômeno se desenvolve, se movimenta de um ponto a outro na história de cada indivíduo-professor e como este movimento cria a profissão professor como categoria de profissionalidade" (MOURA, 2000, p. 48). Nesse sentido, 0 autor apresenta dois conceitos desenvolvidos por Caraça (1951) que favorecem, como fenômeno, a compreensão da formação docente nessa perspectiva teórica, a saber: 0 conceito de Interdependência, ocorre quando "um fenômeno está relacionado com outro fenômeno" (MOURA, 2000, p. 52); e o conceito de Fluência, que corresponde ao ir e vir, ao movimento, às transformações constantes, pois parte do princípio de que nada está estático nem finalizado. Desse modo, a formação apresenta características que identificam o conceito de interdependência em sua constituiç̧ão, pois ocorre em decorrência de necessidades humanas, sociais, individuais e coletivas. Já a fluência pode ser identificada no âmbito do processo formativo devido à premissa de que toda ação humana, ao mesmo tempo que modifica o mundo, altera as concepções do homem. Dessa maneira, ao relacionar-se com o movimento formativo, 0 professor passa por mudanças em decorrência das relações que são estabelecidas entre 0 coletivo, 0 conhecimento e a motivação geradora da inserção no movimento de formação.

Ao partirmos dessas premissas, organizamos um curso de extensão destinado a professores que ensinam matemática na Educação Infantil, com o objetivo de desenvolver, com os participantes, um movimento formativo significativo para seu trabalho docente em relação à matemática. Sendo assim, defendemos que a formação pode contribuir para a aquisição de conhecimentos com uma nova qualidade e, consequentemente, com possíveis repercussões em seu lócus de trabalho, que é a sala de aula.

Em termos metodológicos, essa ação formativa foi estruturada com base na abordagem dialógica, em que os participantes (pesquisadores e professoras) foram considerados ativos e protagonistas do processo. Nessa vertente, o curso de extensão, embora tivesse um planejamento prévio, ganhava contornos mais específicos, decorrentes de interações com as participantes, mediante dúvidas, respostas e debates sobre as várias ações de estudos. Nesse fluxo intercomunicativo, fomos registrando os dados por meio de filmagens, fotografias, gravações de áudio, questionários e tarefas escritas. 
Esse conjunto de instrumentos foi importante para captar indícios do movimento formativo que se evidenciam em enunciados que apontam mudanças de compreensão (MOURA, 2000; 2010). Esse movimento apresenta-se dinâmico, de modo que a relação com o conhecimento e na interação com outras pessoas encontra condições favoráveis a reflexões, revisões e novas elaborações. Em nossa experiência formativa com as professoras da Educação Infantil, buscamos instaurar condições coletivas que estimulassem tais apreensões sobre os conhecimentos matemáticos e 0 ensino na infância. É importante salientar que enxergamos conexões dessas ideias de formação como movimento (MOURA, 2000, 2010) com 0 conceito de Bildung. Podemos refletir com Suarez (2005, p. 193), que toma de empréstimo as palavras de Antoine Berman (1984, p. 142), para dizer que Bildung se refere a um termo alemão que apresenta "[...] forte conotação pedagógica e designa a formação como processo". Além disso, pode ser relacionado à concepção de viagem, tradução, formação cultural e trabalho.

Suarez (2005, p. 195) ainda afirma que o significado de Bildung como viagem está integrado à noção de caminho e destino. Contudo, é importante salientar que não consiste em escolher qualquer caminho, "[...] não consiste em ir a um lugar qualquer, [...] mas, sim, lá onde nós possamos formar e educar". Desse modo, entendemos que os professores, ao buscarem participar do curso de extensão, objeto de análise deste texto, tinham como pressuposto um caminho ou alternativa que pudesse, de algum modo, acrescentar conhecimentos sobre 0 ensino da matemática.

Tal premissa dialoga com reflexões desenvolvidas por Frois (2017, p. 127), quando enuncia:

Em uma viagem, saímos do nosso lugar mais próximo e familiar e nos aventuramos em terras estrangeiras, fora do nosso viver cotidiano; no encontro com a alteridade desses novos ares, somos interpelados a compreender melhor nossa moradia, nossos costumes, nossa identidade. Isso significa que, ao retornarmos, somos enriquecidos não apenas pelo encontro com 0 novo e 0 diferente, mas também com um encontro de nós mesmos. A Bildung pretende materializar essa experiência de viagem e de enriquecimento. Tomar o curso de extensão como uma viagem formativa significa propiciar aos envolvidos uma prática de comprometimento com o formar-se, ação que só pode ser conquistada pelo próprio sujeito, como condição e resultado do trabalho no sentido ontológico do termo. Isso implica a experiência de acessar novos e diferentes saberes docentes [...] e novas experiências pensadas e construídas por todos os professores participantes do curso. 0 resultado desejado é abrir possibilidades de reconstrução dos próprios sujeitos nas várias dimensões de sua existência.

Considerando a formação continuada nessa perspectiva, neste texto apresentamos enunciados que revelam reflexões das professoras cursistas sobre estranhamentos, necessidades, reconhecimentos e sinalizam marcas do movimento de mudanças e de novas expectativas. Em vários extratos, identificamos indícios desse processo de alteração das compreensões sobre os conceitos abordados nos estudos coletivos, bem como sobre 0 trabalho de organização do ensino desses conceitos, conforme verificamos nos enunciados apresentados na próxima seção.

\section{ATIVIDADES DE ESTUDOS COLETIVOS E TRABALHO PEDAGÓGICO DE PROFESSORAS DA EDUCAÇÃO INFANTIL EM MATEMÁTICA}

0 termo atividade é comumente utilizado quando associado a um movimento ou ação. Neste trabalho, adotamos a palavra Atividade baseada na compreensão de Leontiev (1978-2010). Para esse 
autor, o homem realiza diferentes ações, mas se configuram como Atividades somente aquelas que potencializam o desenvolvimento humano, agindo como "[...] processos que são psicologicamente caracterizados pelo facto de aquilo para que tendem no seu conjunto (o seu objecto) coincidir sempre com 0 elemento objectivo que incita o paciente a uma dada actividade, isto é, o motivo (LEONTIEV, 1978, p. 296). Tais compreensões evidenciam que o trabalho do professor, em sua Atividade de ensino, "deve gerar e promover a atividade do estudante" (MOURA et al., 2010, p. 90). Assim, é necessário que, ao ensinar, o professor planeje 0 ensino de maneira intencional, para que 0 aluno se aproprie de conhecimentos culturalmente produzidos. Baseados nessa perspectiva de Atividade, Moura (1996) e Moura et al. (2010) desenvolveram a Atividade Orientadora de Ensino (AOE), caracterizada como

[...] uma proposta de organização que, sustentada pelos pressupostos da teoria histórico-cultural, se apresenta como uma possibilidade para realizar a atividade educativa, tendo por base o conhecimento produzido sobre os processos humanos de construção do conhecimento (MOURA et al., 2010, p. 82-83).

Essa proposta de organização de ensino apresenta três importantes elementos que se configuram em síntese histórica do conceito, situação desencadeadora de aprendizagem e síntese coletiva. A síntese histórica do conceito está relacionada ao momento de estudo do professor sobre a origem e movimento de elaboração do conceito a ser ensinado. A situação desencadeadora de aprendizagem é o segundo momento e trata da ação de ensino que motivará 0 aluno a resolver um determinado problema, vivenciando as necessidades humanas que levaram à construção daquele conceito. 0 terceiro é a forma coletiva em que os envolvidos encontram uma resposta "matematicamente correta" do problema desencadeador (MOURA, 2010). As situações desencadeadoras de aprendizagem podem ser elaboradas mediante três modalidades, a saber: história virtual, jogo ou situação emergente do cotidiano. Em nossas análises, contemplamos dados que situam modos criativos que participantes do curso encontraram para a organização do ensino. Para exemplificarmos tais situações, fizemos recortes de experiências com base em uma história virtual para trabalhar o conceito de medida comprimento e em outra considerada como um jogo para explorar conhecimentos sobre número natural.

Para apresentarmos essas duas situações, organizamos dois episódios de análise que contemplam um conjunto de cenas. Conforme ressaltam Araújo e Moraes (2017, p. 68), estas são organizadas a fim de revelar "[...] as múltiplas determinações, as relações essenciais que possibilitam compreender 0 fenômeno para além da aparência, do imediato". Esses episódios aqui descritos são referentes a duas pesquisas de mestrado de Torezani (2020) e Gomes (2020), vinculadas ao Programa de Pós-Graduação em Educação em Ciências e Matemática - Educimat.

\section{a) Episódio 1: Estudos coletivos e trabalho pedagógico sobre conhecimentos de grandezas e medidas}

Este episódio contempla um recorde de dados da pesquisa de Torezani (2020), que explorou conhecimentos relacionados aos conceitos de grandezas e medidas na ação formativa com as professoras da Educação Infantil. Os dados selecionados para este texto referem-se ao relato de uma das participantes do curso. Esse relato trata de dados sobre a ação de ensino desenvolvida por ela com os seus alunos e aborda conhecimentos da grandeza comprimento. Ressaltamos que, após 
diferentes estudos, organizamos um momento coletivo de planejamento com as professoras, no qual as cursistas tinham como demanda estruturar uma proposta da ação de ensino envolvendo algum conceito abordado no curso e com base nos pressupostos teórico-metodológicos da AOE. Após 0 desenvolvimento desses planejamentos, foram sugeridos a objetivação deles no contexto das salas de aulas onde as professoras atuavam e o compartilhamento das experiências com os demais participantes. Assim, o episódio analisado neste artigo evidencia indícios reveladores de que as discussões coletivas e o movimento de estudo propostos contribuíram para o processo de mudança de qualidade no conhecimento e na organização do ensino da professora.

Ao iniciar seu relato, a professora Marinês ${ }^{4}$ comentou algumas tentativas anteriormente feitas por ela no intuito de abordar conhecimentos matemáticos.

\title{
Quadro 1 - Cena 1.1.
}

\begin{abstract}
Eu tive mais experiências frustradas [falando das tentativas de desenvolver algumas ações de ensino] do que positivas para ter resultado. Eu precisei entender aquilo que estava naquele artigo ${ }^{5}$ [referindo-se a um artigo que havíamos compartilhado sobre o número na THC]. [...] Eu li umas quatro, cinco vezes, pra poder entender e me apropriar daquilo que estava escrito. [...] quando eu compreendi, eu vi o que realmente tinha que ser feito. [...] Então, quase tudo que fazíamos aqui eu repetia com as crianças. Agora, o que vai entrar aqui [mostra no Power point o relato da ação de ensino que realizou com sua turma], foi o que tentei fazer com eles e eu penso que tive algum êxito.
\end{abstract}

Fonte: Dados da pesquisa 2018.

Esses enunciados apontam necessidades da professora relacionadas à leitura e compreensão de modo mais aprofundado do artigo que foi sugerido para estudos e abordava pressupostos da AOE como proposta teórico-metodológica. Esses estudos mencionados por Marinês alteraram suas condições de pensar e organizar as ações de ensino. No questionário a que as professoras responderam no início do curso, quando foi perguntado a respeito de qual era a maior dificuldade/desafio para organizar ações de ensino de matemática na Educação Infantil, a professora registrou a seguinte resposta: "Pouco conhecimento sobre 0 assunto e dificuldade [de] receber orientação" (Resposta questionário inicial, set./2018). Imaginamos que a parte final de sua resposta, quando fala sobre "dificuldades de receber orientações", esteja relacionada à situação de poucas oportunidades de cursos de formação continuada na área de Educação Matemática e trabalho pedagógico na infância, o que reafirma a importância de espaços coletivos de estudos como o que realizamos.

Verificamos que buscar compreender a organização do ensino baseada na Teoria Histórico- Cultural e buscar uma ação que proporcionasse essa proposta alterou os motivos da professora. Essa modificação a pôs em Atividade de aprendizagem docente, pois "[...] um sujeito se encontra em atividade quando o objeto de sua ação coincide com o motivo de sua atividade" (MORETTI; MOURA, 2010, p. 157). Durante o planejamento, a professora Marinês comentou que os estudos coletivos e as proposições das oficinas didáticas do curso estavam sendo importantes para ela, mas que ainda não tinha observado resultados práticos em sua ação docente. Desse modo, demonstrou que suas expectativas ainda precisavam ser alcançadas. Ela narrou que, por várias vezes, tentou realizar diferentes ações desenvolvidas no curso com seus alunos e ainda não estava satisfeita com as repercussões com os alunos. Assim, foi acumulando e reorganizando as experiências até chegar à formulação de

40 s nomes fictícios foram escolhidos pelas próprias professoras.

5 Trata-se do artigo intitulado "Matemática na educação infantil: contribuições da atividade orientadora de ensino para a (re)organização da prática docente", de Mendes e Moretti, 2017. 
uma situação desencadeadora sobre a medida de comprimento e a questão de comparação entre medidas, o que produziu resultados avaliados pela professora como positivos. Esse processo de mudança de qualidade das ações de ensino foi descrito por ela, conforme verificamos no extrato do quadro 2.

Quadro 2 - Cena 1.2.

\begin{abstract}
Eu pensei em fazer algo que pudesse mostrar, com a situação desencadeadora, a diferença e igualdade de tamanhos. Então eu usei o livro da história da Dona Baratinha. Contei a história e apresentei os personagens separados, e eles viam que a relação de tamanho entre 0 candidato a namorado da Baratinha em relação a ela era diferente. Muitos deles, os primeiros eram os maiores, eram bem grandes, e a Baratinha era bem pequenininha, e depois iam aparecendo até que chegou um, pequeninho no mesmo tamanho da Dona Baratinha, e ela se casou com esse. E a gente fez essa comparação. Quem era o maior, quem era o menor, quem tinha tamanho parecido, a diferença e a igualdade de tamanho do bicho para a noiva que era Dona Baratinha. Depois, a gente fez a medição com eles mesmos. E a gente foi conversando. Começamos a fazer a comparação de tamanhos. Então, eu escolhi alguns, pra gente medir. Como a gente vai medir? Aí foi a grande dificuldade. Eles não tinham essa noção. Como que eu vou saber [pergunta a professora para seus alunos]? Ah, mais fulano é o maior e 0 sicrano é o menor! [repete algumas respostas dos alunos]. Não, mas como a gente vai saber disso [pergunta da professora aos alunos]? Aí, eu escolhi alguns [referindo-se a alguns alunos]. Peguei o maior e a menorzinha. Mas eles demoram muito para encontrar uma maneira de como medir, né [comenta a professora]?
\end{abstract}

Fonte: Dados da pesquisa 2018.

Pensar nessa história infantil como situação desencadeadora para abordar um determinado conhecimento matemático foi uma estratégia bastante interessante da professora, pois ela conseguiu organizar uma história virtual que gerou uma necessidade nos alunos de buscar uma solução coletiva para o problema: "como a gente vai medir?" Uma história virtual, trata-se de uma "[...] narrativa que proporciona ao aluno envolver-se na solução de um problema como se fosse parte de um coletivo que busca solucioná-Io, tendo como fim a satisfação de uma determinada necessidade à semelhança do que pode ter acontecido em certo momento histórico da humanidade" (MOURA et al., 2010, p. 224). Esse recurso didático proporciona o envolvimento do aluno em uma ação lúdica e coletiva que favorece apropriações de conhecimentos matemáticos. A ação organizada por ela teve a intenção de ensinar 0 conceito de medida, abordando os diferentes tamanhos dos personagens, o que nos remete à seguinte compreensão:

Como educadores devemos criar possibilidades de colocar a criança em um movimento de apropriação dos conhecimentos matemáticos, ao definir, por um lado, os elementos culturais que necessitam ser assimilados e, por outro, ao elaborar estratégias que permitam alcançar esse objetivo (ARAUJO, 2014, p. 5).

A escolha da professora de utilizar a história para abordar esses conhecimentos ajudou-nos a perceber que estava modificando suas compreensões em relação às possibilidades de trabalhar 0 ensino dos conceitos de grandezas e medidas. Notamos que a professora também não dá respostas prontas, ela questiona os alunos, criando condições que estimulam o interesse e participação na solução do problema. Esses indícios foram reforçados em questionário respondido no fim do curso, quando perguntamos quais conhecimentos sobre a matemática na Educação Infantil, discutidos no curso, haviam promovido mudança nas práticas pedagógicas em sala de aula e identificamos a seguinte resposta de Marinês: "Grandezas e medidas, eu não acreditava que as crianças seriam capazes de entender sobre isso e percebi que é possível sim" (Resposta ao questionário final, Dez. 2018). 
A nova compreensão da professora ajuda a identificar indícios reveladores de outra qualidade no seu pensamento e em suas práticas docentes. Entendemos, com base em Vigotski (2009, 289), que "[...] a passagem para um novo tipo de percepção interior significa passagem para um tipo superior de Atividade psíquica interior. Porque perceber as coisas de modo diferente significa ao mesmo tempo ganhar outras possibilidades de agir em relação a elas".

Ao criar condições de os alunos pensarem em uma maneira como podem realizar a medida e diferentes medições, primeiramente relacionando os tamanhos dos personagens, comparando-os com o maior, menor, igual, diferente, a professora provocou nos alunos a necessidade de irem além das comparações. Isso nos remete às ideias de Caraça (1951) envolvendo os problemas da medida, pois um dos nexos conceituais importantes para a apropriação do conceito de medida é a comparação. A professora continuou o seu relato:

Quadro 3 - Cena 1.3.

\begin{abstract}
Aí um respondeu assim [apresenta a resposta de um aluno]: a minha avó quando vai medir o tamanho da gente ela coloca a gente na parede e risca com um lápis. Aí então eu comecei a fazer isso. Comecei a colocá-los na parede e riscava com 0 lápis e depois eu peguei um barbante. Aí eu vim com um barbante e posicionei dos pés à cabeça deles e cortava e entregava na mão de cada um deles. Eu pensei, como vamos fazer pra que eles visualizassem isso? Coloquei um TNT e fui colocando os barbantes numa ordem em que eles foram medidos. Depois, a gente sentou em volta para poder ver qual o barbante maior. Coloquei a inicial do nome de cada um deles na ponta do barbante, para poder saber. Então eles chegaram à ideia de que Weverton [referindo-se a alunos da sala] era o maior e a Ester era a menor. Foi quando a gente colocou um do lado do outro pela ordem de tamanho. Então, e agora? [pergunta da professora aos alunos]. Como a gente vai classificar isso: o primeiro, o segundo... e o sexto, como era a quantidade de crianças.

Pesquisadora: E eles foram falando?

Marinês: Não. Eles não foram falando não. Depois, era tudo no olho... eles viam e falavam. Depois que colocamos a inicial no barbante, eles viram que o barbante com a inicial tal era maior e outros eram menores. Até eles lembrarem de uma coisa que a gente tinha feito anteriormente de medir com as mãos. [...] fizemos 0 carimbo de mãos ${ }^{6}$ e recortei no outro dia e então a gente foi medir. No TNT com os barbantes, a gente foi pegando um por um e medindo com as mãos. Pegava o barbante, esticava no chão e íamos colocando uma mão, duas mãos, três mãos...para ver quantas mãos precisaria para cobrir aquele barbante que estava ali.
\end{abstract}

Fonte: Dados da pesquisa 2018.

A sugestão apresentada por um aluno trata de um conhecimento espontâneo decorrente de experiências vivenciadas pelo aluno. 0 fato de a professora valorizar esse conhecimento fez-nos perceber indícios de estar entendendo a importância de compartilhar, no coletivo, conhecimentos vivenciados por sujeitos em seus contextos sociais, "[...] de modo que todos possam perceber 0 conhecimento como um bem comum, que, quando assumido coletivamente, torna-se mais útil por permitir a leitura e a intervenção subjetiva na sociedade" (LOPES, 2009, p. 96).

Ao usar o barbante como recurso, algo sugerido a ela durante o planejamento da ação, para demonstrar o resultado da medida marcado na parede, a professora possibilitou que os alunos comparassem seus tamanhos. Essa comparação visual dos barbantes colados no TNT permitiu que eles conseguissem verificar pela observação quem era maior, menor e igual, resolvendo essa primeira necessidade da medida, a comparação. Porém, não permitiu encontrar um número mediante a medição com outro em instrumento padrão, porque, além de o barbante ser um objeto de natureza contínua (LANNER de MOURA, 1995), não foi usado como unidade de medida, mas como transposição da altura das crianças. Por meio do relato, observamos que a professora proporcionou outra experiência

6 Refere-se à transferência das mãos das crianças para o papel, para se tornar um instrumento de medida. 
de medição dos alunos, no intuito de resolver a questão da medida registrada na parede, levando-os a pensar outra possibilidade de medir, que foi utilizar representações de suas mãos como unidade de medida-padrão. Esse movimento de troca de instrumentos, para atender à necessidade e resolver o problema em questão, permitiu que os envolvidos se aproximassem da história do conceito e da lógica que o envolve.

Percebemos que a maneira como a professora mediou a ação foi baseada em discussões e ações desenvolvidas no curso, em uma das quais, pedimos que as professoras fizessem a medição da mesa a que estavam, podendo utilizar qualquer instrumento/objeto ou estratégia para fazer a medição. Na ocasião, as professoras tinham acesso a vários objetos, como lápis, caneta, papel sulfite A4, barbante, entre outros. Uma das nossas intenções era ver quais possibilidades as professoras iriam encontrar de forma coletiva, para realizar a medição de modo não padronizado, associando-as as suas práticas diárias. Destacamos que ações formativas que possibilitam ao professor um movimento de construção do significado do conceito trabalhado possibilitam apropriações de conhecimentos, uma vez que "[...] compreender a essência das necessidades que moveram a humanidade na busca de soluções que possibilitaram a construção social e histórica dos conceitos é parte do movimento de compreensão do próprio conceito" (MORETTI; MOURA, 2011, p. 442). Além disso, quando priorizam o trabalho coletivo na busca da resolução de um determinado problema, promovem acordos e negociações que favorecem a compreensão do ensino mediado (MOURA, 2011) e contribuem para que 0 professor reelabore suas práticas docentes. Por esse caminho, compreendemos que a ação de medir a mesa desenvolvida em um dos encontros contribuiu para que a professora organizasse a ação de ensino, favorecendo aos alunos condições para que discutissem e construíssem o significado do conceito de medir por meio das necessidades que foram sendo geradas.

A possibilidade encontrada de medir o comprimento do barbante, utilizando a mão como unidade de medidas, ocasionou outra situação (quadro 4), pois a unidade escolhida não continha "[...] um número inteiro de vezes na grandeza a ser medida" (LANNER DE MOURA, 1995, p. 47).

Quadro 4 - Cena 1.4.

\begin{abstract}
E aí, quantas mãos que tem no barbante do maior? [pergunta aos alunos]. E aí a gente foi contando com as mãos e 0 que ficava faltando a gente foi fechando com os dedos. Tantas mãos e tantos dedos. Só que também eles não souberam representar [referindo-se ao momento de registrar a resposta no quadro] assim: se era 5 mãos, o tamanho do barbante de fulano eles não sabiam como iam representar. Eu disse pra eles: vamos dar um pauzinho pra cada mão que a gente colocar. Mas eles quiseram fazer o desenho da mão... Nas mãos de Weverton, por exemplo, ele tinha 8 mãos e aí ele foi desenhar, ele desenhou 8 mãos. Ele não desenhou 8 pauzinhos, que ficaria mais fácil. Então, a gente terminou com eles usando as mãos e a gente tentando fazer um padrão de medição nas outras coisas.
\end{abstract}

Fonte: Dados da pesquisa, 2018.

Isso fez com que a professora e os alunos terminassem a medida utilizando dedos. Essa ação foi interessante porque levou os alunos à necessidade de "[...] fracionar a unidade para expressar exatamente a dimensão da grandeza em partes da unidade" (LANNER DE MOURA, p. 1995, p. 47). A solução encontrada favoreceu que os alunos estivessem pensando outros modos de medir para resolver o problema em questão. A estratégia encontrada pela professora ajuda a perceber que ela tem pensado possibilidades de resolver situações de medidas que envolveram objetos de natureza contínua. Ela havia vivenciado uma situação semelhante a essa, quando realizava a ação de medir 
a mesa. Na ocasião, 0 instrumento/objeto que 0 grupo do qual ela fazia parte utilizou para fazer a medição havia sido o papel sulfite A4. Durante essa medição, as professoras envolvidas perceberam que 0 resultado não seria com número, então decidiram coletivamente fracionar por meio de dobras no papel sulfite A4, para finalizar a medição. Notamos as tentativas de registro do resultado e a necessidade de padronizar o instrumento de medida. Mas a professora não detalhou como ocorreu essa questão da padronização.

Os enunciados revelam que os momentos de conversas que a professora teve com a turma durante a ação proporcionaram um ambiente de interação entre os alunos e ela, favorecendo discussões e levantamentos de hipóteses para solucionar o problema de medida. Tais atitudes vão ao encontro do que discutimos ao longo do curso sobre a importância de proporcionar ambiente coletivo no qual os alunos tenham oportunidade de levantar hipóteses e soluções (MOURA, 1996). Esse ambiente coletivo é propício para aprendizagens, tendo em vista que será na "[...] interação com os outros sujeitos [-] no caso com os colegas e com o professor - que 0 aluno vai se apropriar do conhecimento" (LOPES, 2009, p. 95).

Dando sequência ao relato, ela apresenta o retorno à história virtual da D. Baratinha para resolver a questão da medida dos bichos (quadro 5).

Quadro 5 - Cena 1.5.

[...] voltamos aos bichos da história. Então, as figuras a gente foi fazendo com mãos também e com dedos. Quantas mãos e quantos dedos aquela figura daria pra gente ver em medida de mão e de dedo se era menor ou maior, de acordo com eles haviam falado só com o olho, né? E a gente foi medindo, só que a figura tem uma comparação diferente, porque a figura não é o tamanho real do animal, mas é naquela proporção da figura que eles puderam comparar o que era maior e o menor. Fonte: Dados da pesquisa, 2018.

Outro enunciado interessante foi o da professora retornar à medição inicial dos personagens da história, utilizando a mão como unidade de medida padronizada, para que eles verificassem o que haviam respondido inicialmente com base nas observações visuais. Retornar à tarefa inicial, apresentando a solução encontrada pelo grupo para realizar a medição, evidenciou que toda ação realizada havia sido organizada intencionalmente, uma vez que a professora retomou a situação inicial que havia sido a comparação dos tamanhos dos personagens. Os alunos puderam perceber que a solução por eles encontrada resolveu o problema inicial de medida por comparação. Além de comparar os comprimentos dos animais e da unidade de medida definida (mão), verificaram quantas vezes a unidade cabia no comprimento de cada animal e, por fim, encontraram uma expressão numérica para a comparação. Essa ação intencionalmente organizada pela professora mostrou indícios reveladores de que a professora estava no movimento de pensar ações de ensino que se aproximam da proposta de organização de ensino abordada na Ação Formativa:

Ao organizar o ensino na perspectiva da AOE, primeiramente o professor terá que se apropriar do conceito que deseja que seus estudantes aprendam, o que exige estudo. A partir deste momento, criará a Situação Desencadeadora de Aprendizagem (SDA), que contém um problema que deve considerar a gênese do conceito que quer ensinar e deve explicitar a necessidade de tal conceito, o motivo dele ter sido criado pela humanidade. Essas SDA podem ser apresentadas aos alunos a partir de diferentes 
recursos metodológicos, como jogos, situações emergentes do cotidiano e histórias virtuais (MARAFIGA, 2017, p. 81).

Quando questionada por uma pesquisadora sobre a participação e compreensão dos alunos, a professora concluiu que eles se envolveram e buscaram solução para realizar as medições.

Quadro 6 - Cena 1.6.

Pesquisadora: E aí, eles participaram? Foi melhor? Teve mais sucesso em relação ao movimento deles? Marinês. Sim. De participar numa solução. Porque antes [referindo-se a outras ações que havia proposto aos alunos] eles não pensavam em solução. Era só: [repete a fala dos alunos] não sei. Não sei, e acabou.

Pesquisadora: Mas, desse modo, você conseguiu que eles pensassem?

Marinês: Sim. Eles pensaram baseados em alguma coisa que eles já haviam visto antes. Eu achei interessante essa da marca na parede, né? [referindo-se à sugestão dada por aluno, baseada no que a avó fazia].

Fonte: Dados da pesquisa, 2018.

De acordo com a professora, outras ações de ensino anteriormente desenvolvidas não provocaram nos alunos a necessidade de encontrar soluções para possíveis problemas apresentados. Inferimos que tais ações por ela mencionadas não se constituíram como Atividade de aprendizagem e a percepção dela mudou mediante a leitura do texto "Matemática na educação infantil: contribuições da atividade orientadora de ensino para a (re)organização da prática docente" (MENDES; MORETTI, 2017) e das discussões que ocorreram na ação formativa. É preciso organizar intencionalmente um ensino, pensando ações que provoquem necessidades no aluno de modo que se aproximem dos conceitos que se pretende ensinar, pois uma Atividade se configura como tal quando 0 objeto coincide com 0 motivo da atividade, objetivando-se nas ações (MOURA, et al., 2010). Os dados apresentados dão-nos indícios reveladores de que a ação de ensino por ela relatada se constituiu em uma situação que provocou necessidades nos alunos, motivando-os a realizar ações com a finalidade de solucionar questões que foram surgindo e possivelmente entraram em Atividade de aprendizagem.

Com base nos enunciados, verificamos que essa ação organizada pela professora se aproximou das ideias discutidas na ação formativa. As tarefas propostas favoreceram que os alunos tivessem maior experiência com o objeto estudado, oportunizando acesso a objetos culturais e utilizando-os como ferramentas para atender às necessidades objetivas da medição. Entendemos que sua forma de ação favoreceu que os alunos tivessem condições de se apropriarem de conhecimentos historicamente construídos pela humanidade.

Durante a realização das tarefas propostas, percebemos que os alunos puderam pensar sobre as questões que envolveram a situação, levando-os a uma busca coletiva e favorecendo trocas, compartilhamento de conhecimentos para atender às necessidades que emergiram no decorrer da ação.

Concluímos a análise desse episódio, inferindo que os motivos que levaram a professora a estudar 0 artigo coincidiram com 0 objeto e estimularam a ação de ensino desenvolvida (LEONTIEV, 2010). Acreditamos que o motivo de estudar 0 artigo para se apropriar do conhecimento e da proposta teórico-metodológica adotada por nós na ação formativa e, assim, organizar o ensino de modo a favorecer a aprendizagem dos alunos, se constituiu em Atividade para a professora e para os alunos. Dizemos que a professora tanto se apropriou de novos conhecimentos quanto proporcionou novas aprendizagens aos alunos, dando-lhes condições de se aproximarem da ideia do conceito de medida, 
envolvendo comparação, uso de instrumentos não padronizados e indicação de um número para representar a comparação.

\section{b) Episódio 2 - Estudos coletivos e trabalho pedagógico sobre conhecimentos de números naturais}

A pesquisa de Gomes (2020) foi fonte de dados para este episódio, que apresenta enunciados referentes à ação de ensino de duas professoras participantes da ação formativa, como resultados de suas aprendizagens. A ação de ensino desenvolvida pelas professoras Claudia e Aline, intitulada "bola ao cesto", foi realizada como desdobramento da ação de estudo desenvolvida na formação e ocorreu de forma conjunta pelas professoras, pois, na mesma unidade de ensino, trabalhavam com crianças na faixa etária entre 5 e 6 anos. Essas condições possibilitaram uma parceria mais estreita entre as professoras desde o momento do planejamento até a execução da ação de ensino.

Segundo as professoras, a proposta realizada por elas teve os seguintes objetivos: "[... estimular a coordenação motora; noção de espaço e força; concentração; noção de ordenação; reconhecimento dos números e as quantidades que eles representam; desenvolver ideia de soma e desenvolver diferentes maneiras de registro de quantidades" (Dados da pesquisa, out./2018). Podemos entrever, mediante a redação desses objetivos, certas relações com o movimento de estudo e planejamento coletivo do curso. Eles estão relacionados com as áreas de conhecimentos matemáticos abordados no movimento de estudo proposto no curso, que podem ser observados nestes objetivos: estimular a noção de espaço, grandezas e medidas; estimular a noção de força e com número natural; relacionar a noção de ordenação, reconhecimento dos números e quantidades, ideia de soma e registros. Esses objetivos indicam conexões com as ações de estudo sobre o planejamento e a organização da ação de ensino. É importante indicar que, durante o curso, foram abordados diferentes conhecimentos relacionados ao movimento lógico-histórico de desenvolvimento do número natural, por meio de situações desencadeadoras de aprendizagem. Essas situações envolveram uma história virtual para explorar o estudo da correspondência um a um e outra situação que considerou o modo de contagem utilizado pela tribo Papuas da Nova Guiné, como forma de estudar a ideia de ordenação, utilizando partes do corpo como instrumento para o controle de quantidades. Além disso, desenvolvemos duas situações com jogos, denominadas "jogo dos feijões", em que discutimos sucessão numérica e a ideia de base como elemento importante para a apropriação do sistema de numeração, e "jogo do boliche", para discutir relações entre contagem e a necessidade de registro simbólico para o controle de quantidades.

Amorim e Moretti (2017, p. 203) afirmam que, "[...] no processo de formação docente, é que os professores se apropriam de conceitos a serem ensinados em atividades de ensino", tendo em vista que no movimento de elaboração de "[...] uma situação desencadeadora de aprendizagem o professor coloca em ação os seus conhecimentos conceituais e didáticos [...] ressignificando-os no espaço coletivo" (AMORIM; MORETTI, 2017, p. 203). Esses indícios mostram que as professoras atribuíam sentidos das ações de estudos na ação de ensino.

As cursistas professoras Claudia e Aline relataram que, no primeiro momento da ação de ensino, possibilitaram às crianças, de forma coletiva, a escolha e definição de qual tipo de cesto e qual tipo de bola eram os mais adequados para a realização do jogo "Bola ao Cesto", disponibilizando dois tipos de recipientes para o cesto e três tipos de bolas. Essa proposição apresentou-se como um problema a ser solucionado pelas crianças, no qual era necessário observar atributos dos objetos em função de um dos objetivos a serem alcançados na tarefa: conseguir lançar a bola ao cesto (quadro 7). 
Quadro 7 - Cena 2.1.

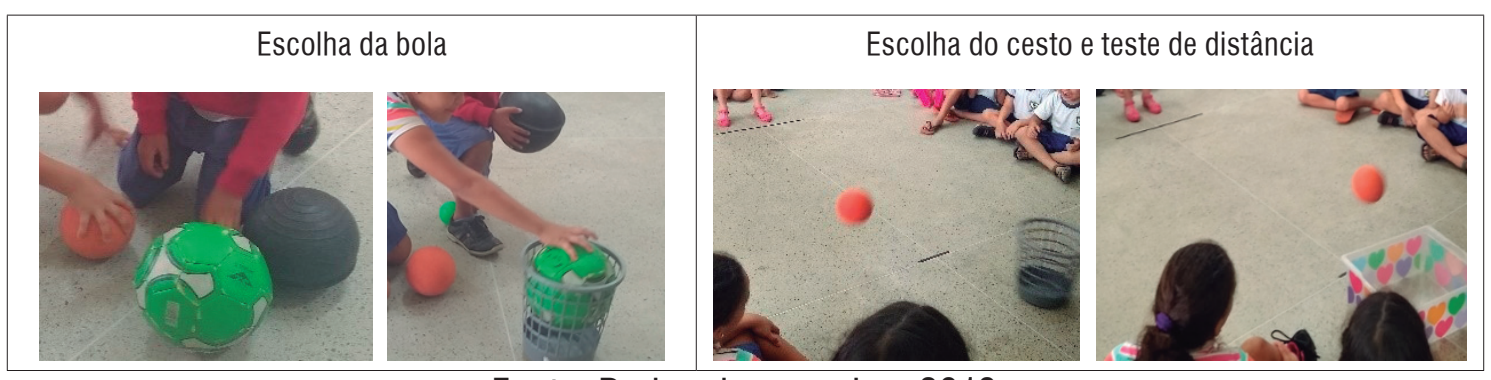

Fonte: Dados da pesquisa, 2018.

Com esse objetivo orientador das ações, as crianças lidaram com a questão da distância e da força com que manuseavam os instrumentos, visando atingir 0 alvo e, desse modo, alcançar o sucesso esperado na brincadeira. Para solucionarem esse problema, as crianças realizaram experimentos relacionados ao peso, tamanho da bola, em relação ao cesto e à força empregada no arremesso da bola. Definiram, de forma coletiva, a bola e o tipo de cesto ideal para a realização do jogo. Essas escolhas apresentaram-se como possibilidade de exploração de conceitos matemáticos, como medidas e proporcionalidade, além de conceitos como força e velocidade.

Após a solução do primeiro problema, iniciou-se 0 jogo, que consistia no arremesso da bola ao cesto. As crianças foram organizadas em duas equipes, em que todas arremessaram a bola duas vezes. A cada acerto da bola, a criança realizava o registro da pontuação no quadro, para, assim, controlar a quantidade de pontos adquiridos durante 0 jogo.

No momento do registro da pontuação, as professoras observaram que as crianças de ambas as equipes utilizavam os signos numéricos para controlar a pontuação adquirida. Essa percepção possibilitou que as regentes adequassem a proposição da tarefa, a fim de despertar nas crianças a necessidade de adotar estratégias de registro que favorecessem o controle da pontuação da equipe. Desse modo, "[...] lançamos o desafio: como faremos para somar os pontos para saber qual foi a equipe vencedora?" (Dados da pesquisa, Out/2018). Esse desafio evidenciou o papel ativo das professoras no processo de mediação, observando e tomando decisões que acreditavam qualificar a ação com base nas respostas das crianças. Esses indícios dialogam com o que Moura et al. (1996, p. 19) defendem, quando afirmam:

0 professor é organizador da atividade e por isso sabe o que está em jogo no espaço da sala de aula: 0 conteúdo, as principais dificuldades em apreendê-lo, as respostas que indicam se o conceito está sendo apreendido ou não, e as solicitações necessárias para redirecionar a busca de um nível mais avançado de conhecimento.

Esse modo de compreender 0 trabalho pedagógico indica que as professoras criaram possibilidades para explorar o conhecimento numérico das crianças. A proposição do problema de pontuação das equipes aponta que a estratégia de registro utilizada pelas crianças, no primeiro momento, satisfazia a necessidade imediata e individual de controlar a quantidade de pontos por meio da utilização do símbolo numérico. Entretanto, não favorecia o controle da pontuação total da equipe. Isso reforça a importância do olhar atento do professor, ao desenvolver ações de ensino. 0 professor, comumente, compreende as limitações do aluno, bem como os indicativos que demonstram a possibilidade de 
avanço, ou seja, a orientação do ensino que leva a aprendizagens é evidenciada pela ação do professor. Nesse caso, a percepção das limitações do registro com signo numérico gerou nas professoras a necessidade de adotar uma nova estratégia de abordagem que fomentaria novas necessidades para as crianças encontrarem a pontuação total de cada equipe. Moura (2000, p. 39) aponta que os conhecimentos do professor em atividades

[...] poderão colocar em movimento os mecanismos de passagem do pensamento prático para o estratégico, pois terá de explicitar o seu modo de fazer o ensino. E isso significa colocar em prática as suas concepções ao definir o conteúdo a ser ensinado, a formação que considera relevante e as competência que pretende desenvolver.

Ou seja, a intervenção na ação de registro das crianças só foi possível devido ao conhecimento apresentado pelas professoras tanto na elaboração da tarefa quanto em seu desenvolvimento. Nesse redirecionamento, a necessidade das crianças de controlar a quantidade de pontos adquiridos, por equipe, remete à necessidade humana de ter controlado quantidades nos primórdios do desenvolvimento do conceito de número, quando utilizavam diferentes estratégias e instrumentos para o controle das quantidades.

Possibilitar esse tipo de situação em ações de ensino dialoga com a concepção de ensino com base na perspectiva Histórico-Cultural e das proposições da AOE e pressupõe que "[...] seja criada nos estudantes a necessidade de se apropriar de conceitos" (MOURA et al., 2016, p. 116). Entretanto, é essencial que a apropriação dos conceitos ocorra "[...] de modo que suas ações sejam realizadas em busca da solução de um problema que o mobilize para a atividade de aprendizagem - a apropriação de conhecimentos" (MOURA et al., 2016, p. 116). Isso é notório nos dados do Quadro 8 :

\section{Quadro 8 - Cena 2.2.}

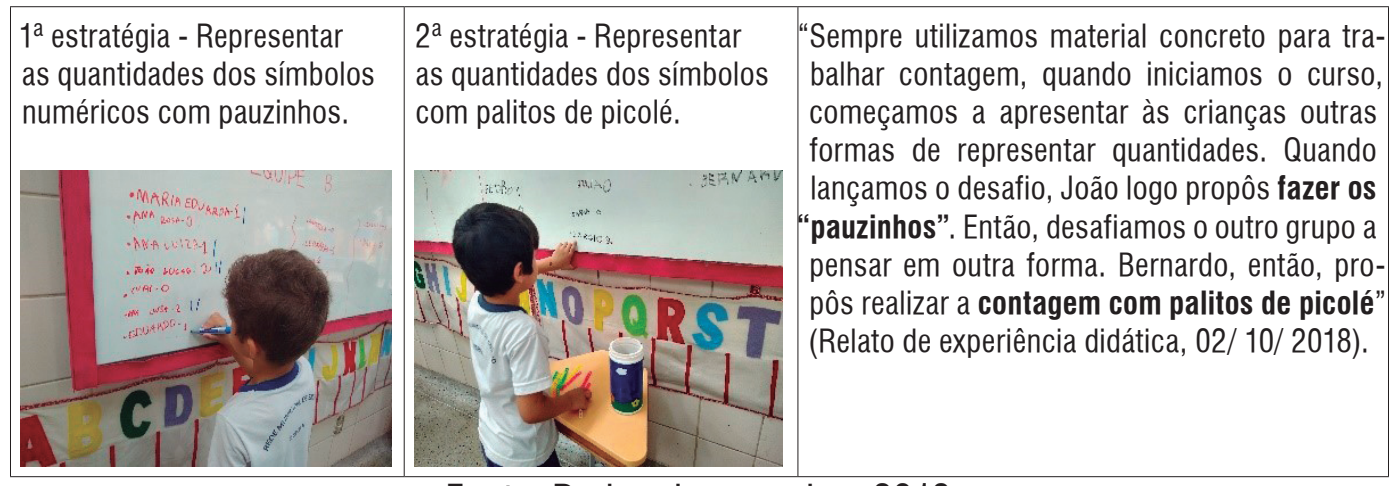

Fonte: Dados da pesquisa, 2018.

As formas adotadas pelas crianças, com utilização de tracinhos ou palitos de picolé para encontrarem a resposta sobre qual a equipe tinha alcançado o maior número de pontos, revelam conexões com experiências anteriores, especialmente quando as professoras relatavam que trabalhavam com material concreto. 0 extrato também evidencia o movimento de mudança em ações cotidianas do ensino como reflexo do movimento de estudo do curso, pois elas afirmaram: "[...] quando iniciamos o curso, começamos a apresentar às crianças outras formas de representar quantidades" (Relato de experiência didática, 02/10/2018). 
Para ampliarmos os indícios de mudança de qualidade, trazemos enunciados em outras situações. A professora Claudia relatou: "[...] nesses 14 anos de atuação como professora, nunca tinha levado para meus alunos essa reflexão [...] sobre o que são números, que história vem por traz desse sistema" (Dados da sala virtual, 2018). No movimento de estudo do curso, afirmou: "[...] aprendi que os números surgiram e se adaptaram através da necessidade humana, como acontece até os dias atuais, o homem está em constante evolução" (Dados da sala virtual, 2018). Essa compreensão do número pela professora tornou-se essencial para uma nova qualidade de sua ação de trabalho, pois a participante afirmou: "[...] hoje em minha prática educativa, não chego mais com os conceitos prontos. Esses são os números, a sequência, o calendário" (Dados da sala virtual, 2018). A estratégia de ensino foi alterada, pois a professora Cláudia disse: "[...] hoje tento despertar neles a curiosidade em querer aprender mais. Quando instigamos a curiosidade infantil, conseguimos resultados surpreendentes". Fica evidente a motivação da professora em utilizar novas estratégias em sua ação de trabalho, ao compreender a constituição do conceito e seus elementos.

Do mesmo modo, a professora Aline indicou mudanças em decorrência da ação de formação. Em dados do questionário final, a professora apontou: "A correspondência um a um, a história dos números, numeral corpo e numeral objeto [...]", conhecimentos explorados na ação de estudo sobre o número natural "[...] me fizeram entender a importância de compreender as quantidades e de representá-las de diferentes formas, antes de inserir a grafia dos números na educação infantil” (Resposta questionário final, professora Aline, 2018).

Em outro extrato, a professora Aline (Resposta questionário final, 2018) ressaltou: "Através do curso consegui compreender que a matemática precisa fazer sentido para as crianças, que elas conseguem compreender melhor os conteúdos que trabalhamos, quando os mesmos já possuem significado para elas". Essa conclusão reforça que a percepção e compreensão do ensino da matemática para crianças da Educação Infantil foram alteradas. Inferimos que esses indícios sobre outro modo de conceber os conhecimentos matemáticos sobre número natural foram possíveis por meio dos estudos coletivos, teóricos e metodológicos propostos na ação de formação. De acordo com Marco e Moura (2016, p. 25-26): "As situações vivenciadas e refletidas no coletivo podem levar os sujeitos a melhor apreender o mundo em que vive". Além disso, contribuem para a aquisição de "[...] novos instrumentos para intervir em seu meio cultural e a desenvolver um 'novo' olhar sobre o significado de ensinar e aprender, nas relações de sala de aula" (MARCO; MOURA, 2016, p. 25-26). A ação de ensino realizada e os enunciados apresentados pelas professoras indicam que 0 caráter coletivo da ação formativa, o processo de estudo com base no movimento lógico e histórico dos conceitos e o desenvolvimento da ação de ensino promoveram mudanças qualitativas na forma de ensinar e conceber o número natural no trabalho pedagógico na Educação Infantil, realizado pelas professoras participantes.

\section{CONSIDERAÇ̃̃ES FINAIS}

As discussões tecidas neste texto tiveram 0 objetivo de evidenciar relações entre ações de estudos coletivos propostos na formação e o processo de mudança de qualidade na organização do trabalho pedagógico das participantes, relacionada ao ensino de conhecimentos matemáticos na Educação Infantil. Observamos que as ações de estudos trabalhadas na ação formativa se mostraram favoráveis para proporcionar o desenvolvimento de novas aprendizagens, ocasionando mudança de qualidade no ensino de grandezas e medidas e de número natural. 
Notamos que as situações coletivas desenvolvidas no curso e trabalhadas com professoras, pautadas na AOE, favoreceram a compreensão delas sobre a necessidade de os alunos vivenciarem situações de ensino que contemplassem a essência do conceito a ser ensinado. Os reflexos nas ações de ensino evidenciados nos relatos apresentados e a tomada de consciência pelas professoras de suas aprendizagens no decorrer e ao finalizar o curso mostram indícios do movimento de mudança qualitativa nas relações entre as ações de estudo coletivos e na organização do ensino de conhecimentos matemáticos na Educação Infantil.

Entendemos que os extratos apresentados apontam que os estudos realizados nos encontros não ficavam estagnados, mas fomentaram mudanças em concepções das professoras e, consequentemente, repercutiram em ações didáticas. Assim, concluímos este artigo com a inferência de que os indícios de aprendizagens das participantes, manifestadas nos episódios das pesquisas, nos permitem compreender que a ação formativa constituiu uma Atividade de formação na perspectiva Histórico-Cultural, pois produziu uma nova qualidade na organização e concepção sobre o ensino de matemática na infância.

\section{REFERÊNCIAS}

AMORIM, G. M., MORETTI, V. D. Matemática na educação infantil: contribuições da atividade orientadora de ensino para a (re)organização da prática docente. Revista Inter-Ação, v. 42, n. 1, p. 194-213, jan./abr. 2017. Disponível em: http://dx.doi.org/10.5216/ia.v42i1.41860. Acesso em: 03 set. 2017

ARAÚJO, E. S. 0 Ensino de Matemática na Infância. Encontro Nacional de Didática e Prática de Ensino (ENDIPE), 2014. Disponível em: https://bit.ly/35rxVJA. Acesso: 20 jun. 2020.

ARAÚJO, E. S.; MORAES, S. P. G. Dos princípios da pesquisa em educação como atividade. In: MOURA, M. 0. de (Org.). Educação escolar e pesquisa na teoria histórico cultural. São Paulo: Loyola, 2017, p. 47-70.

BEATÓN, G. A. La educación como medio de resistencia y lucha de los pueblos por la justicia social. Cadernos de pesquisa em Educação - PPGE/UFES, v. 19, n. 46, jul./dez. 2017, p. 107-126. Disponível em: https://bit.ly/35iUq3s. Acesso em: 20 jul. 2020.

CARAÇA, B. de J. Conceitos Fundamentais da Matemática. Lisboa: Tipografia Matemática, 1951.

CEDRO, W. L. 0 motivo e a atividade de aprendizagem do professor de matemática: uma perspectiva histórico-cultural. Tese (Doutorado em Educação) - Programa de Pós-Graduação da Faculdade de Educação da Universidade de São Paulo, São Paulo, 2008.

FRANCO, P. L. J.; LONGAREZI, A. M. Elementos constituintes e constituidores da formação continuada de professores: Contribuições da teoria da atividade. Revista: Educação e Filosofia Uberlândia, v. 25, n. 50, p. 557-582, jul./dez. 2011. Disponível em: https://bit.ly/3kms8LR. Acesso em: 19 jun. 2020.

FROIS, I. D. de 0.0 entorno da Vale S.A. na perspectiva do direito à cidade: da miopia verde à catarse do pó preto. Dissertação (Mestrado). Programa de Pós-Graduação em Ensino de Humanidades. Instituto Federal do Espírito Santo, Vitória, 2018. 
GLADCHEFF, A. P. Ações de estudo em atividade de formação de professores que ensinam matemática nos anos iniciais. São Paulo: 2015. Tese (Doutorado) - Faculdade de Educação, Universidade de São Paulo, São Paulo, 2015.

GOMES. D. de S. Formação continuada de professores da Educação Infantil na perspectiva Histórico-Cultural: número natural em debate. Vitória: 2020. Dissertação (Mestrado) - Programa de Pós-Graduação em Educação em Ciência e Matemática, Instituto Federal do Espírito Santo, Vitória, 2020.

LANNER DE MOURA, A. R. A medida e a criança pré-escolar. 1995. Tese (Doutorado em Educação) Universidade Estadual de Campinas, Campinas-SP,1995.

LEONTIEV, A. N. 0 desenvolvimento do psiquismo. Lisboa: Horizonte Universal, 1978.

LEONTIEV, A. N. Os princípios psicológicos da brincadeira pré-escolar. In: Linguagem, Desenvolvimento e Aprendizagem. Tradução Maria da Pena Villalobos. 11. ed. São Paulo: Ícone, 2010. (Coleção Educação Crítica).

LEONTIEV, AN. Actividad, Conciencia, Personalidad. México: Editorial Cartago, 1984.

LEONTIEV, A. N. Uma contribuição à Teoria do Desenvolvimento da Psique Infantil. In: Linguagem, Desenvolvimento e Aprendizagem. Tradução Maria da Pena Villa-Lobos. 11. ed. São Paulo: Ícone, 2010. (Coleção Educação Crítica).

LOPES, A. R. L. V. Aprendizagem na docência em Matemática: o Clube de Matemática como espaço de formação inicial de professores. Passo Fundo-RS: Ed. Universidade de Passo Fundo, 2009.

MARAFIGA, A. W. 0 planejamento e a atividade principal da criança: vivências de futuras professoras na educação infantil. Santa Maria: 2017. Dissertação (mestrado) - Programa de Pós-Graduação em Educação. Universidade Federal de Santa Maria, Santa Maria/RS, 2017.

MARTINS, L. M. A formação social da personalidade do professor: um enfoque vigotskiano. Campinas, SP: Autores Associados, 2015.

MARCO, F. F.; MOURA, M. O. Quando ações desenvolvidas por professores em processo de formação se constituem em atividade orientadora de formação docente: alguns indiciadores In: Lopes, A. R. L. V.; Araújo, E. S.; Marco, F. F. de. (Org.). Professores e futuros professores em atividade de formação. 1 ed. Campinas: Pontes Editores, 2016, v. 1, p. 19-39.

MORETTI, V. D.; MOURA, M. 0. de. 0 sentido em movimento na formação de professores de matemática. ZETETIKÉ, Campinas, v. 18, n. 34, p. 155-180, jul./dez. 2010.

MORETTI, V. D.; MOURA, M. 0. de. Professores de matemática em atividade de ensino: contribuições da perspectiva histórico-cultural para a formação docente. Ciência \& Educação, v. 17, n. 2, p. 435-450, 2011.

MOURA, M. O. (Org.). Controle de Variação de Quantidades: atividade de ensino. São Paulo: FEUSP, 1996.

MOURA, M. 0. de. (Org.). Atividade Orientadora de Ensino: unidade entre ensino e aprendizagem. Revista Diálogo Educacional, Curitiba, v. 10, n. 29, p. 81-109, jan./abr. 2010. 
MOURA, M. 0. de. A aprendizagem Inicial do Professor em Atividade de Ensino. In. LOPES, A. R. L. V., TREVISOL, M. T. C.; PEREIRA, P. S. (Org.) Formação de Professores em Diferentes Espaços e Contextos. Campo Grande: Editora UFMS, 2011.

MOURA, M. 0. de. A atividade de ensino como ação formadora. In: CASTRO, A. D.; CARVALHO, A. M. P. (Org.). Ensinar a ensinar. São Paulo: Pioneira, 2001.

MOURA, M. 0. de. 0 educador matemático na coletividade de formação: uma experiência com a escola pública. Tese de livre docência. Universidade de São Paulo, Faculdade de Educação, São Paulo, 2000.

MOURA, M. 0. de. (Coord.) A atividade pedagógica na teoria histórico-cultural. Brasília: Liber livro, 2010.

MOURA, M. O. (Org.). A atividade Pedagógica na teoria Histórico-cultural. Campinas-SP: Autores Associados, 2016.

RADFORD, L. A teoria da objetivação e seu lugar na pesquisa sociocultural em educação matemática. In: MORETTI, V. D.; CEDRO, W. L. (org.). Educação matemática e a histórico cultural: um olhar sobre as pesquisas. Campinas, SP: Mercado de Letras, 2017. p. 229-262.

SAVIANI, D. Formação de professores: aspectos históricos e teóricos do problema no contexto brasileiro. Revista Brasileira de Educação, v. 14, n. 40, jan./abr. 2009. p. 143-155.

SUAREZ, Rosana. Nota sobre o conceito de Bildung (Formação Cultural). Kriterion, Belo Horizonte, n. 112, p. 191-198, dez. 2005.

TOREZANI, Fabiany Cezário Dias. Grandezas e medidas na educação infantil: uma experiência em formação continuada. Dissertação (Mestrado) - Programa de Pós-Graduação em Educação em Ciência e Matemática, Instituto Federal do Espírito Santo, Vitória, 2020.

VIGOTSKI, L. Psicologia pedagógica. São Paulo: Martins Fontes, 2010.

VIGOTSKI, L. S. A construção do pensamento e da linguagem. São Paulo: Martins Fontes, 2009.

RECEBIDO EM: 30 jun. 2020

CONCLUÍDO EM: 21 set. 2020 